\title{
INSTRUCTORS' CHALLENGES IN IMPLEMENTING E-LEARNING IN A PUBLIC UNIVERSITY IN YEMEN
}

\author{
Hanan Aldowah \\ Center for Instructional Technology and Multimedia, Universiti Sains Malaysia; \\ hanan_aldwoah@yahoo.com \\ Samar Ghazal \\ Center for Instructional Technology and Multimedia, Universiti Sains Malaysia; \\ samarghzl@yahoo.com \\ Irfan Umar \\ Center for Instructional Technology and Multimedia, Universiti Sains Malaysia; irfan@usm.my
}

\begin{abstract}
Public universities in developing countries are confronted with many challenges in implementing elearning. Hence, this research aims to identify the major challenges faced by a public university in Yemen in establishing e-learning as a successful medium for their teaching and learning activities. This paper will discuss these challenges from the instructors' perspectives. This quantitative study using survey approach by means of a questionnaire was used to examine the instructors' views about the challenges that they face in implementing e-learning in their university. The results revealed four main challenges faced by the instructors which hinder the successful implementation of e-learning in the university. These challenges are: individual challenges, course challenges, contextual challenges, and technological challenges. In specific, the instructors faced contextual challenges in terms of organizational and cultural aspects. In addition, technological challenges were found to play an important role in the implementation of e-learning. The study also found that instructors need to apply the appropriate pedagogical models to deliver their e-learning courses. Furthermore, the instructors are facing individual challenges in terms of the amount of time needed to deal with e-learning requirements and the need for financial support for both the instructors and students. The main contribution of this research is that it addresses the challenges that influence the successful implementation of e-learning in the public university sector in Yemen as this area of research lacks theoretical and empirical studies.
\end{abstract}

Keywords: E-leaning, Challenges, University, Yemen

\section{INTRODUCTION}

In the last ten years, the use of e-learning has been increasing rapidly and it has become an important system offered by most colleges and universities all over the world. This comes as the consequence of the innovative transfer of knowledge and learning which has been influenced by the advent of the Internet and other Information and Communication Technologies (ICT) (Qureshi, Ilyas, Yasmin, \& Whitty, 2012). E-learning is currently the common term used to describe the various uses of ICT to enhance learning and teaching. It takes the form of online courses and training, by which the courses and training are delivered via the Internet (Al-Shboul, 2013; Yoloye, 2015).

E-learning has become a worldwide phenomenon to facilitate various aspects of learning and training. Learning facilitated by the new technology or e-learning is transforming learning and education forms in ways that extend beyond the efficient delivery value of traditional approaches (Garrison, Anderson, \& Archer, 2003; Wilson \& Gapsiso, 2014). It assembles a new pedagogical context, develops new roles for instructors and students, as well as provides more options for students to create meaningful learning environments that promote and enhance the learning experience. However, teaching and learning in an e-learning environment can present new challenges to instructors and students participating in this online learning environment (Archambault, Larson, Oliver, Roycroft, \& Rose, 
2015; Archambault, Warren, \& Foley, 2010). Therefore, these new challenges must be determined, identified, and addressed in order to overcome and ensure the success of e-learning.

Universities have been motivated to adopt e-learning to transform traditional learning environments and create more efficient and attractive learning experiences (Abdelraheem, 2006). Successful implementation of e-learning requires an understanding of the issues that promote and support the effective use of the new technology (Bhuasiri, Xaymoungkhoun, Zo, Rho, \& Ciganek, 2012). In addition, the implementation of e-learning in universities should be considered as part of educational reform process. For effective use of e-learning, a great deal of attention needs to go into its implementation. When universities promote e-learning use, they need to understand their instructors' and students' attitudes towards its use. Instructors' attitudes are considered as a major predictor of the use of new technologies in instructional settings (Gulbahar \& Kalelioglu, 2015).

University education in Yemen has witnessed large expansion in the last two decades. The enhancement of university education requires improving its responsiveness to the needs of the society and of development, be able to keep pace with the advances and changes in the fields of technology as well as the ability to face the challenges of the times. Therefore, and as part of a program to establish an IT institution that will link Yemeni universities to a single information network, an IT center was established in the Ministry of Higher Education (ESCWA, 2009). Moreover, most of the universities have been provided with learning resources including computers, Internet, projectors, television sets, etc. Furthermore, most of the instructors in the universities have been trained in the field of computer skills. A number of public and private university facilities are also established to enable the teaching of ICT disciplines such as computer science, communication engineering, engineering and programming, and information science, but the curricula are not being updated enough to keep pace with rapid developments.

Based on the literature, successful implementation of e-learning will provide many benefits to the universities. It can promote collaborative learning, deepen understanding, help learners think and communicate creatively, increase learners' motivation, as well as offer better access to information (Khan, Hossain, Hasan, \& Clement, 2012). Unfortunately, developing countries including Yemen are still distance away from getting the full benefit and advantage of e-learning because of many challenges. These challenges are fundamental and critical that need to be identified and addressed for the successful implementation of e-learning in a developing country (Mahmud \& Gope, 2009; Yoloye, 2015) like Yemen. The review of literature has further revealed that very few studies have been conducted the challenges of e-learning implementation in the context of Yemen, especially in public universities (Al-Haderi, 2013; Aljaaidi, 2009). This study will therefore bridge the gap that exists in the current knowledge on challenges in e-learning implementation, especially in the Yemeni context.

\section{Problem Statement}

E-learning systems have become the need of time, thus, some of the Yemeni universities are spending funds for the acquisition of these systems, but are unable to achieve purposeful goals (Thabet \& Kalyankar, 2014). Although the government is committed to implement ICT in the education process, learning in an electronic environment is still low in Yemen. The process seems to be affected by a number of barriers and challenges. Therefore, identifying these challenges in implementing e-learning in higher education may lead to a better understanding of the causes of reluctance to the use e-learning (Tarus et al., 2015). Recently, there have been call for the insertion of the views of instructors about these challenges (Afshari, Kenayathulla, Idris, Ibrahim, \& Razak, 2013; Al-Shboul, 2013; Bhuasiri et al., 2012; Cox, 2010; Rhema, Miliszewska, \& Sztendur, 2013). Therefore, this study is focused on investigating the instructors' challenges during the implementation of e-learning in a Yemeni public university.

\section{Individuals Challenges}

Individual challenges in the context of this study mean the issues and problems that are related to the individual circumstances and personal characteristics. 


\section{Course Challenges}

Course challenges refer to the problems that are related to the e-learning course such as content pedagogical model, the delivery mode of the course, and flexibility.

\section{Contextual Challenges}

Contextual Challenges in this study refer to the problems that are related to the context of the organization (university setting) and the context of society such as culture, rules and regulations.

\section{Technological Challenges}

Technological Challenges refer to the problems that are related to technological requirements such as computers, LMS, infrastructures and so forth.

Fig 1 represents the four main challenges and their related constructs and factors

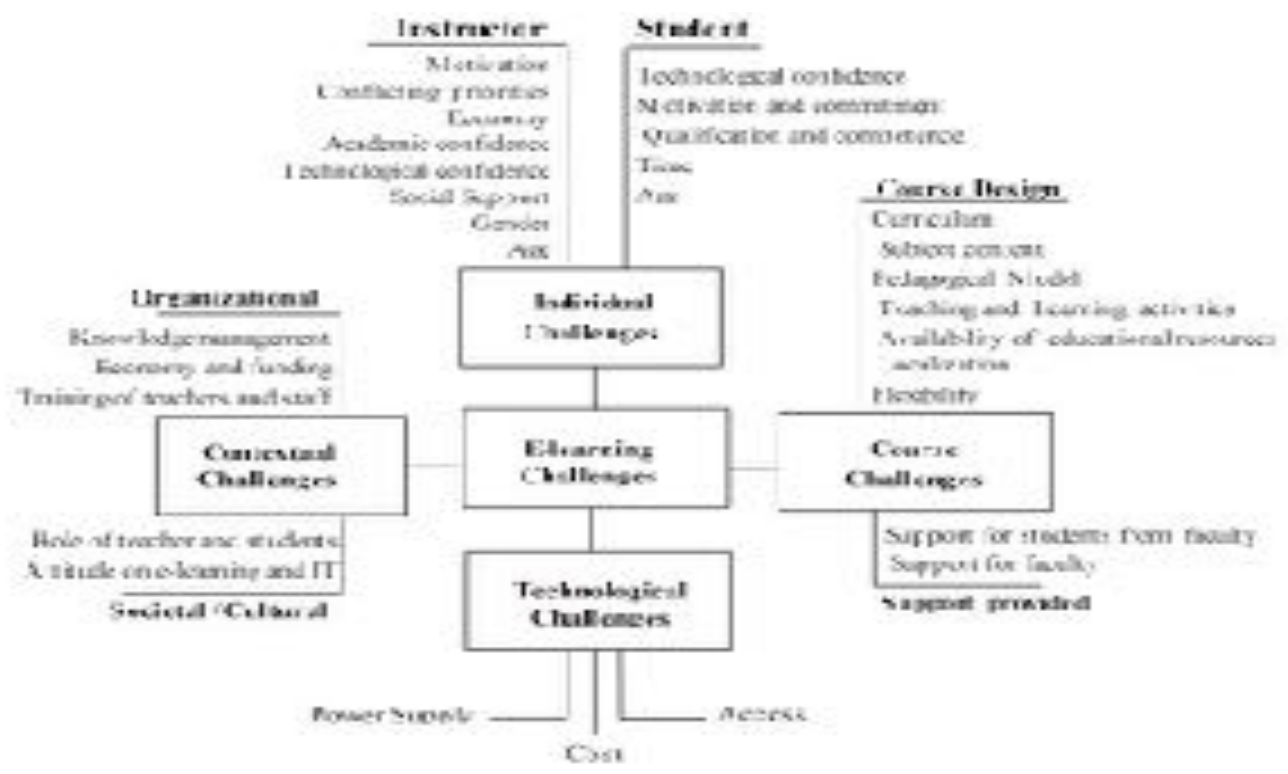

Fig 1: Challenges of Implementing E-learning in a Public University

\section{Research Objectives}

1. To examine the challenges of the implementing e-learning in a public university in Yemen in terms of Individual, Course, Context and Technology.

\section{Research Questions}

1. What are the instructors' views of the challenges that they face as a result of the implementation of e-learning in terms of Individual, Course, Context, and Technology.

\section{Methodology}

This study involved a population of 497 instructors at the Hodiedah University, Yemen. For sampling purposes, a sample of 107 instructors from 16 faculties was chosen. The sample included males and females, junior and senior instructors focusing on the instructors who have direct relationships with elearning project in the university and have access to the resources of e-learning content. A total of 120 sets of questionnaire have been prepared and distributed to the respondents. However, only 107 sets of questionnaire have been successfully collected and analyzed, which constitute $89.2 \%$ response rate from the survey. In this study, seven demographic variables were investigated, which include gender, age, teaching experience, ICT experience, Level of ICT, e-learning training, and e-learning experience. In addition, there are four main variables in this study, which are the four challenges of implementing e-learning include: individual challenges, course challenges, contextual challenges, and technological challenges. These four variables comprised of 7 sub-constructs and 30 factors. The closed-ended items in the questionnaire were validated to suit the context of the study. The participants were asked to rate 
their agreement of each item of the survey on a 4-point Likert Scale (except for the demographic information), where 1= Strongly Disagree, 2= Disagree, 3= Agree, 4= Strongly Agree.

The instrument consisted of 46 items and they are divided into four main sections. The results in Table 1 show that alpha coefficients for all construct dimensions are high. Alpha values for all constructs exceeded the 0.70 lower limit of acceptability (Hair, Black, Babin, Anderson, \& Tatham, 2006).

Table 1: Sub-Constructs' Reliability

\begin{tabular}{l|c|c|c}
\hline \multicolumn{1}{c|}{ Construct } & Sub-Construct & $\begin{array}{c}\text { No of } \\
\text { Items }\end{array}$ & Cronbach's Alpha ( $\alpha)$ \\
\hline \multirow{2}{*}{ Individual challenges } & Instructors & 10 & 0.772 \\
\cline { 2 - 4 } & Students & 10 & 0.786 \\
\hline \multirow{2}{*}{ Course Challenges } & Course Design & 8 & 0.797 \\
\cline { 2 - 4 } & Support Provided & 3 & 0.857 \\
\hline \multirow{2}{*}{ Contextual challenges } & Organizational & 4 & 0.837 \\
\cline { 2 - 4 } & Social / Cultural & 5 & 0.858 \\
\hline Technological Challenges & Technology & 4 & 0.837 \\
\hline
\end{tabular}

\section{Data Analysis and Findings}

\section{Instructors' Challenges in Implementing E-learning}

This section answers the question of the research: what are the challenges in implementing e-learning in a public university in Yemen in terms of the Individual, Course, Context, and Technology? In order to answer this research question and to identify the most crucial challenges for e-learning implementation in the university, the level of agreement and the mean average are used. The mean score for each challenge (Individual Challenges, Course Challenges, Contextual Challenges, and Technological Challenges) are described and analyzed. Data was evaluated using the mean score based on the table which was adapted from Landell, (1997) as well as Saari and Rashid (2013). As shown in Table 2, the level of agreement for each challenge was determined by the following criteria (equation): Interval Width = maximum point - minimum point $\backslash$ number of levels.

$$
=4-1 \backslash 3=1.00
$$

These criteria have also been applied by (Arabiyat, 2011; Azman, Silva, Samah, Man, \& Shaffril, 2013; Dweik \& Awajan, 2013).

Table 2: The criteria of agreement level

\begin{tabular}{cc}
\hline Mean Range & Interpretation \\
\hline $3.1-4.0$ & High Level of Agreement \\
$2.1-3.0$ & Moderate Level of Agreement \\
$1.00-2.0$ & Low level of Agreement \\
\hline
\end{tabular}


In general, the findings revealed that all the four categories of challenges - Individual, Course, Context, and Technology as identified earlier - influence their teaching and learning activities in the elearning environment. Nevertheless, this agreement was at different levels. Therefore, the results are listed with the mean score for each challenge to determine the level of agreement on these challenges among the participants. The results also showed that, in general, the instructors indicate a high level of agreement for contextual challenges as an important challenge factor in implementing e-learning and recorded the highest mean score (3.51), followed by Technological Challenges with a mean score of 3.47 and Course Challenges (3.12). Meanwhile, they reported a moderate mean score for Individual Challenges (2.11).

\section{Instructors' Challenges in Terms of Individual factors}

Individual challenges consist of two factors involving instructors' aspect and students' aspect. Table 3 shows the mean score of the two aspects. Firstly, instructors' aspect involving ten items to measure this challenge. The ten items cover the five sub-factors of instructors' challenges, which include technological confidence, motivation and commitment, qualification and competence, time, and age, with a mean score of 1.69. However, for the students' aspect, the respondents' views were measured by eight sub-factors including; motivation, conflicting priorities, economy, academic confidence, technological confidence, social support, gender and age. The mean score of students' aspect is 2.53 . In general, the mean score of the individual challenges for the two variables (instructors and students aspects) is 2.11 (for 20 items), which is considered a moderate level of agreement. It proves that the respondents agree that individual challenges are one of the main challenges to implement e-learning system.

Table 3: Mean Score of Individual challenges

\begin{tabular}{cccc}
\hline $\begin{array}{c}\text { Individual } \\
\text { challenges }\end{array}$ & Mean & $\begin{array}{c}\text { Std. } \\
\text { Deviation }\end{array}$ & Score \\
\hline $\begin{array}{c}\text { Instructors' } \\
\text { aspect }\end{array}$ & 1.69 & 0.408 & Low \\
$\begin{array}{c}\text { Students' } \\
\text { aspect }\end{array}$ & 2.53 & 0.417 & Moderate \\
\hline Total & $\mathbf{2 . 1 1}$ & $\mathbf{0 . 2 8 6}$ & Moderate \\
\hline
\end{tabular}

In general, the results revealed that the majority of the instructors' sample surveyed disagreed with the statements related to instructors' aspect. However, the results indicated that most of the respondents agreed [Strongly Agree: 29\% (n: 31) and Agree: $44.9 \%$ (n: 53)] with economy as an important challenge that they face during the implementation process with the highest mean scores among other challenges while gender had the lowest mean score among all items with 1.83. The result indicates that most of the respondents disagreed with the given statement [Strongly Disagree $=43$ respondents $(40.2 \%)$, Disagree $=44$ respondents $(41.1 \%)]$. The mean scores of items ranged from 1.50 to 2.03 while the mean of the Students' aspect survey items ranged from 1.83 to 3.04 .

\section{Instructors' challenges in Terms of Course}

There are two main challenges for the course which are course design and support provided. Table 4 indicates the means of these two factors. Firstly, support provided with a mean score (3.41) while course design came in second place with a mean score (2.94). The total mean score of the course challenges items is 3.12 (high). 
Table 4 :Mean Score for Course challenges

\begin{tabular}{lccc}
\hline $\begin{array}{c}\text { Course } \\
\text { challenges }\end{array}$ & Mean & $\begin{array}{c}\text { Std. } \\
\text { Deviatio } \\
\mathbf{n}\end{array}$ & $\begin{array}{l}\text { Scor } \\
\mathbf{e}\end{array}$ \\
\hline Course Design & 2.94 & 0.278 & $\begin{array}{l}\text { Moderat } \\
\text { e }\end{array}$ \\
\hline $\begin{array}{l}\text { Support } \\
\text { Provided }\end{array}$ & 3.41 & 0.417 & High \\
\hline \multicolumn{1}{c}{ Total } & $\mathbf{3 . 1 2}$ & $\mathbf{0 . 4 6 9}$ & High \\
\hline
\end{tabular}

Eight items were used to measure the course design items. The eight items cover seven sub-factors comprising; Curriculum, Pedagogical Model, Subject-Content, Teaching and Learning activities, Localization, Flexibility, Availability of Educational Resources. The mean scores of the course design items ranged between 2.41 and 3.48. The results revealed that most of the participants agreed with all the items related to the course design as challenges for the implementation of e-learning. Meanwhile, five statements were used to measure the support provided challenge, which cover the two sub-factors of the support provided challenges including support for students from instructors and support for instructors from university. All the items that are related to the support provided recorded high scores as challenges face instructors during the implementation. Meanwhile, the mean scores of support provided items ranged from 3.23 to 3.55 .

\section{Instructors' Challenges in in terms of Context}

This study has also identified the two factors for the contextual challenges, namely, organizational and social/ cultural. Table 4 shows the mean scores for the two factors of the contextual challenges. The highest score was reported by organizational challenges (mean score: 3.57 ), mean followed by Social / Culture challenges with a mean score of 3.45. In general, the total mean score of the contextual challenges factors is 3.51, which is considered a high level of agreement as a challenge of implementing e-learning in the university.

Table 5 Mean Scores of Contextual Challenges

\begin{tabular}{cccc}
\hline $\begin{array}{c}\text { Contextual } \\
\text { challenges }\end{array}$ & $\begin{array}{c}\text { Mean } \\
\text { Score }\end{array}$ & $\begin{array}{c}\text { Std. } \\
\text { Deviation }\end{array}$ & score \\
\hline $\begin{array}{c}\text { Organizationa } \\
\text { 1 Challenges }\end{array}$ & 3.57 & 0.452 & High \\
$\begin{array}{c}\text { Social/ } \\
\text { Culture } \\
\text { Challenges }\end{array}$ & 3.48 & 0.463 & High \\
\hline Total & 3.51 & 0.407 & High \\
\hline
\end{tabular}


The respondents were also asked to provide their views on the organizational challenges that they are facing in implementing e-learning in their university. Four items were used to cover the three subfactors of organizational challenges including; management knowledge, economy and funding, training of instructors and staff. Based on the findings, the instructors demonstrated a high level of agreement for the items related to the organization with a total mean score of 3.57. All the items recorded high scores and the mean scores of the items ranged from 3.24 to 3.71. With regard to societal /culture challenge, five items were used to cover the three sub-factors including, Role of Instructor and Student, Attitude on E-learning and IT, Rules and Regulation. The instructors recorded a high level of agreement with all items related to societal /culture challenges. The total means score for societal / culture is 3.48. The mean, scores for the items ranged from 3.44 to 3.51 . The results show that the majority of respondents agreed with items related to the societal and culture.

Table 6 Mean Scores of Technological Challenges

\begin{tabular}{cccc}
\hline $\begin{array}{r}\text { Technological } \\
\text { Challenges }\end{array}$ & Mean & $\begin{array}{c}\text { Std. } \\
\text { Deviati } \\
\text { on }\end{array}$ & Score \\
\hline Access & $3.34 \downarrow$ & 0.857 & High \\
Cost & 3.43 & 0.715 & High \\
Infrastructures & 3.37 & 0.680 & High \\
Power Supply & $3.72 \uparrow$ & 0.491 & High \\
\hline Total & 3.47 & 0.511 & High \\
\hline
\end{tabular}

\section{Instructors' challenges of implementing e-learning in terms of Technology}

In general, the mean score of the technology challenges items is 3.47 - a result which indicates that technology is seen as an important challenge that may affect the successful implementation of elearning. In this dimension, four items were used to measure this challenge; Access, Cost, Infrastructure, and Power Supply. The results indicate that all the items related to technological challenges recorded high scores. The mean score of technological items ranged from 3.34 and 3.72.

\section{Discussion}

This study has described the instructors' views pertaining to the challenges in implementing e-learning in a public university in Yemen. In general, majority of the instructors who were involved in the study agreed that all the four challenges (individual, course, contextual and technological) do exist and hinder the implementation of e-learning in their institution. This result is in agreement with the results of Wang et al., (2008). However, these challenges were at different levels of importance as perceived by the instructors. In the context of Yemen, contextual challenges were highlighted as the most crucial concern that hinder the implementation e-learning, followed by the technological challenges. The contextual challenges include the need to make provision for training of instructors and staff in the university. In addition, there is a need for financial resources for e-learning activities. Moreover, there is a lack of planning, e-learning awareness, and a lack of management support. This result is in line with the ones reported in a previous research (Alkharang \& Ghinea, 2013) who obtained the same result in the context of Kuwait. As for the technological challenges, the most common issues are absence of sufficient power supply, access to computers and other technologies which come in line with same findings in most developing countries (Mahmud \& Gope, 2009; Yoloye, 2015). Then, course challenges came in third place and the most common emerging issues are the need for suitable pedagogical model for e-learning, e-learning curriculum, and the lack of educational resources in the university. Finally, individual challenges were identified as the least important challenges in the context of Yemen. This is in contrast to the findings by several authors (e.g., Al-Adwan \& Smedley, 2012; Cech \& Bures, 2004; Khan, 2005) in which their research have positioned individual challenges in the first place. Meanwhile, based on their findings, Andersson and Gronlund (2009) have placed 
course challenges in the first place. This is due to the fact that most of the instructors are young adults and have high ICT experience, and therefore, individual challenge is not considered as an issue.

\section{Conclusion}

This study has investigated the instructors' views about the challenges in the implementation of elearning in a public university in Yemen. In this study, individual, course, contextual and technological challenges have been identified as a main challenges that face e-learning implementation in the university. According to the findings of the study, the most important challenges of the implementation of e-learning in Yemen are related either to organizational (context), technological (technical) or course issues. However, individual challenges were reported to be the least concern in the respondents' perspective. The finding showed that the instructors are ready and motivated to implement e-learning, however, they need more training related to e-learning technology. This study concludes that successful implementation of e-learning can be achieved if these challenges are addressed properly. An awareness of any challenge that instructors face could lead to the development of solutions for overcoming these challenges. This research will help the decision makers of the universities to recognize the challenges faced by the instructors and recommend the necessary actions to reduce or eliminate those challenges.

\section{Acknowledgement}

Authors would like to thank Universiti Sains Malaysia (USM) for the financial support.

\section{References}

Abdelraheem, A. Y. (2006). The Implementation of E Learning in the Arab Universities: Challenges and Opportunities. Proceedings of DLI 2006, 145-155.

Afshari, M., Kenayathulla, H. B., Idris, A. R., Ibrahim, M. S., \& Razak, A. Z. A. (2013). Factors affecting the effective implementation of e-learning in educational institutions. Turkish Online Journal of Science \& Technology, 3(3).

Al-Adwan, A., \& Smedley, J. (2012). Implementing e-learning in the Jordanian Higher Education System: Factors affecting impact International Journal of Education and Development using Information and Communication Technology, 8(1), 121-135.

Al-Haderi, S. (2013). The effect of self-efficacy in the acceptance of information technology in the public sector. International Journal of Business and Social Science, 4(9), 188-198.

Al-Shboul, M. (2013). The level of e-Learning integration at The University of Jordan: Challenges and opportunities. International Education Studies, 6(4), p93.

Aljaaidi, K. S. Y. (2009). Girls' educational crisis solving through the adoption of e-learning system: The case of Hadhramout University Alkharang, M. M., \& Ghinea, G. (2013). E-learning in Higher Educational Institutions in Kuwait: Experiences and Challenges. E-learning, 4(4).

Andersson, A., and , \& Gronlund, A. (2009). A conceptual framework for e-learning in developing countries. The electronic Journal of information systems in developing Countries, 38(1), 1-16.

Arabiyat, B. (2011). Organizational Climate Prevailing in Al-Balqa Applied University/Faculty of Princess Alia University from the Viewpoint of the Faculty Members: Case Study. International Journal of Human Resource Studies, 1(2), 104-110.

Archambault, L., Larson, J., Oliver, W., Roycroft, A., \& Rose, R. (2015). Research Panel on Supporting Teachers and Accessibility in K-12 Online and Blended Learning Contexts. Paper presented at the Society for Information Technology \& Teacher Education International Conference.Archambault, L., Warren, A., \& Foley, R. W. (2010). Sustainability Education Framework for Teachers: Developing sustainability literacy through futures, values, systems, and strategic thinking. Education, 2010.

Azman, A., Silva, J. L. D., Samah, B. A., Man, N., \& Shaffril, H. A. M. (2013). Relationship between attitude, knowledge, and support towards the acceptance of sustainable agriculture among contract farmers in Malaysia. Asian Social Science, 9(2), p99.

Bhuasiri, W., Xaymoungkhoun, O., Zo, H., Rho, J. J., \& Ciganek, A. P. (2012). Critical success factors for e-learning in developing countries: A comparative analysis between ICT experts and faculty. Computers \& education, 58(2), 843-855.

Cech, P., \& Bures, V. (2004). E-learning implementation at university. Paper presented at the Proceedings of the 3rd European Conference on e-learning, Paris, France.

Cox, M. (2010). The changing nature of researching information technology in education. Researching IT in education: theory, practice and future directions, 11-24. 
Dweik, B. S., \& Awajan, N. W. (2013). Factors that Enhance English Language Teachers' Motivation in Jordanian Secondary Schools. English Linguistics Research, 2(1), p33.

ESCWA. (2009). (Economic and Social Commission for Western Asia)

National Profile of the Information Society in Yemen (2009 November). Retrieved from, http:// www.escwa.un.org/information/publications/edit/upload/sdpd-09-4.pdf

Garrison, D. R., Anderson, T., \& Archer, W. (2003). A theory of critical inquiry in online distance education. Handbook of distance education, 1, 113-127.

Gulbahar, Y., \& Kalelioglu, F. (2015). Competencies for e-Instructors: How to Qualify and Guarantee Sustainability. Contemporary Educational Technology, 6(2).

Hair, J., Black, W., Babin, B., Anderson, R., \& Tatham, R. (2006). Multivariate data analysis (6 ed.). Englewood Cliffs, NJ: Pearson Prentice Hall.

Khan, B. (2005). Learning features in an open, flexible and distributed environment. AACE Journal, 13(2), 137-153.

Khan, M., Hossain, S., Hasan, M., \& Clement, C. K. (2012). Barriers to the Introduction of ICT into Education in Developing Countries: The Example of Bangladesh. Online Submission, 5(2), 61-80.

Landell, K. (1997). Management by menu. London: Wiley and Sons Inc.

Mahmud, K., \& Gope, K. (2009). Challenges of implementing e-learning for higher education in least developed countries: a case study on Bangladesh. Paper presented at the Information and Multimedia Technology, 2009. ICIMT'09. International Conference on.

Rhema, A., \& Miliszewska, I. (2010). Towards e-learning in higher education in Libya. Issues in Informing Science and Information Technology, 7(1), 423-437.

Rhema, A., Miliszewska, I., \& Sztendur, E. (2013). Attitudes towards e-learning and satisfaction with technology among engineering students and instructors in Libya. Paper presented at the Proceedings of the Informing Science and Information Technology Education Conference.

Saari, H. A., \& Rashid, A. M. (2013). Competency level of employability skills among the apprentices of the national dual training system: a comparative analysis of industry perception by company status. International Journal of Education and Research, 1(11), 1-12.

Tarus, J. K., Gichoya, D., \& Muumbo, A. (2015). Challenges of implementing e-learning in Kenya: A case of Kenyan public universities. The International Review of Research in Open and Distributed Learning, 16(1).

Thabet, T. S. A., \& Kalyankar, N. (2014). The Effect of E-Learning Approach on Students'Achievement in Fraction Math Course Level 5 at Yemens Public Primary School. Global Journal of Computer Science and Technology, 14(2).

Wang, S.-C., Cowie, B., \& Jones, A. (2008). Challenges of e-learning for university instructors in Taiwan. Paper presented at the The 16th International Conference on Computers in Education (ICCE 2008). Taipei, Taiwan.

Wilson, J., \& Gapsiso, N. D. (2014). Achieving the Millennium Development Goals in Africa: Harnessing E-Learning Potentials. Developing Country Studies, 4(15), 28-34.

Yoloye, E. O. (2015). New Technologies For Teaching and Learning: Challenges For Higher Learning Institutions In Developing Countries. Information Communication Technology (ICT) Integration to Educational Curricula: A New Direction for Africa, 250. 